\title{
Albergues de carretera de Carlos Arniches y Martín Domínguez. Un patrimonio que hay que conservar
}

\begin{abstract}
La red de albergues de carretera del Patronato Nacional del Turismo fue una estructura hotelera destinada a fomentar el turismo con automóvil particular, que se integró en la red nacional de paradores durante cuatro décadas del siglo XX. De los doce albergues que compusieron en su día la red quedan ocho en pie. La demolición del albergue de Antequera (Málaga) y el estado de deterioro que presenta hoy el antiguo albergue de Bailén (Jaén), en estado de ruina y oculto desde la calle, obligan a reconsiderar la situación de este último y a adoptar medidas para su rehabilitación y protección.
\end{abstract}

María José Rodríguez Pérez, Antonio Ceresuela Puche | arquitectos

URL de la contribución <www.iaph.es/revistaph/index.php/revistaph/article/view/3558>

Las innovaciones arquitectónicas que se produjeron a comienzos del siglo pasado dejaron en Andalucía su huella de forma temprana, con anterioridad a la propia consolidación del Movimiento Moderno, mediante la construcción de dos albergues de carretera que fueron promovidos por el organismo oficial dedicado al turismo, el Patronato Nacional del Turismo (1928-1939).

El albergue de carretera para automovilistas constituyó un tipo hotelero nuevo destinado a prestar servicio de restauración, alojamiento y suministro de combustible para el automóvil en las principales carreteras del Plan Nacional de Firmes Especiales.

La idea inicial del albergue tomó forma en las páginas del diario El Sol, en la sección "la arquitectura y la vida" que desarrollaban los arquitectos Carlos Arniches y Martín Domínguez con carácter semanal. Aquella pionera propuesta caló hondo en los responsables del Patronato Nacional del Turismo, que la adoptaron con el objeto de promover establecimientos iguales destinados al turismo automovilista. La materialización de la propuesta comenzó con la convocatoria de un concurso de anteproyectos en el que debía ser elegido el prototipo que serviría para construir los doce establecimientos programados. Arniches y Domínguez resultaron adjudicatarios del encargo y desarrollaron el proyecto en 1929, que se construyó en dos fases sucesivas. En la primera fase se ejecutó de forma simultánea la obra civil correspondiente a los doce albergues (1930-1931), todos igua- les aunque con algunas pequeñas variantes en función del acceso desde la carretera, la orientación, la topografía, las vistas y la propia geometría de la parcela; y en la segunda fase se fueron completando las diferentes acometidas y la urbanización, que motivó su entrada en funcionamiento de forma escalonada entre 1931 y 1946.

Andalucía contó con dos de estos albergues, uno en Antequera (Málaga) y otro en Bailén (Jaén), que junto a los otros diez repartidos por la geografía española constituyeron una estructura hotelera con entidad propia, incluida dentro de la red de alojamientos turísticos del Estado, la Red de Paradores.

\section{Albergue de Bailén \\ En un principio se había programado la construcción de un albergue en Motril, pero el subdelegado regional del Patronato, Luis Antonio Bolín Bidwell, decidió el cambio de ubicación a favor de Bailén. El Ayuntamiento realizó un papel de mero intermediario en la adquisición de los terrenos, ya que la compraventa del solar denominado bóveda o huerta de Arteaga la realizó directamente el Estado en agosto de 1930.}

Martín Domínguez realizó la dirección de obra y la inauguración del establecimiento se produjo el 23 de enero de 1933, que lo convertía, tras el de Manzanares (Ciudad Real), en el segundo albergue abierto al público. Posteriormente, el Patronato fue realizando las obras de acondicionamiento de la parcela por administración 
directa hasta su conclusión poco antes del inicio de la Guerra Civil, que determinaría su abandono. El acondicionamiento del inmueble para su reapertura al público se realizó entre 1940 y 1941. La Dirección General del Turismo (1939-1951), organismo oficial que sustituyó al Patronato tras la guerra, decidió ampliar la huerta para conseguir el autoabastecimiento del albergue mediante la adquisición de los terrenos colindantes. La reforma se materializó en nuevas compraventas a favor del Estado en 1942 y 1947, que permitieron la construcción de un nuevo pabellón de cocheras y surtidor de gasolina, según el diseño y materiales estandarizados para el conjunto de los albergues.

Las primeras ampliaciones se consumaron en los años cuarenta dentro del volumen construido, gracias a la transformación de las habitaciones del servicio en habitaciones de clientes y la redistribución interior general.

En los años cincuenta el Ministerio de Información y Turismo (1951-1977) reconsideró la capacidad hotelera del albergue y tras varios tanteos de ampliación del edificio existente se decidió construir un edificio nuevo en los terrenos adyacentes, que se consumó en los años sesenta con el proyecto de parador del arquitecto Manuel Sainz de Vicuña. El albergue quedó relegado a vivienda del administrador del parador y con el tiempo dejó de utilizarse por lo que devino rápidamente en ruina.

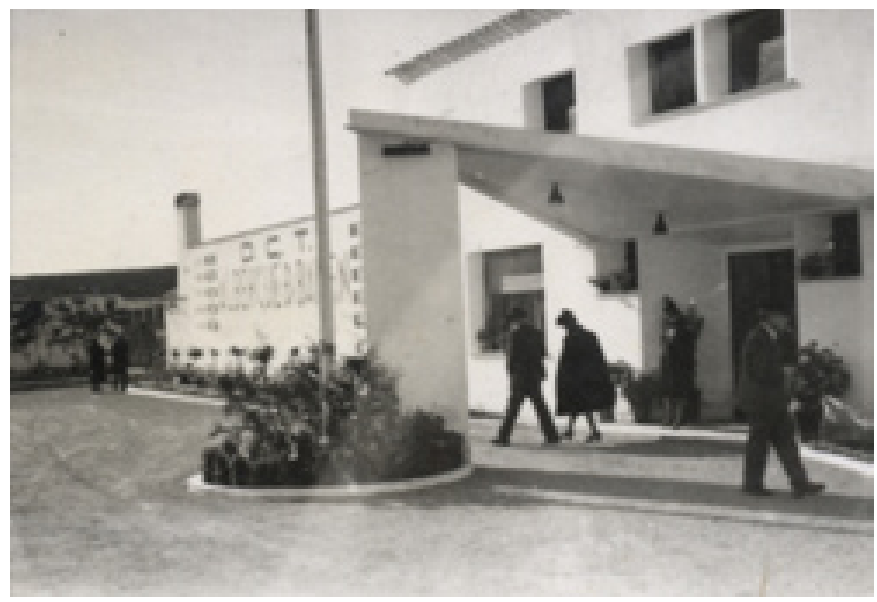

Albergue de carretera en Bailen (ca. 1933) | foto MECD, Archivo General de la Administración, Fondo Patronato Nacional de Turismo, F-00332-08-033

\section{Albergue de Antequera}

El albergue se ubicó por decisión de Luis Antonio Bolín en un montículo cercano a la confluencia de las carreteras, situado en las afueras de la ciudad y próximo a los terrenos en los que se estaba construyendo el monumento dedicado al Sagrado Corazón de Jesús. En este caso los terrenos fueron adquiridos por el Ayuntamiento y cedidos gratuitamente a favor del Estado con destino a la construcción del pequeño establecimiento hotelero.

El edificio estaba terminado en 1931 y sin embargo quedaba por ejecutar la obra de urbanización. El Patronato sufrió restricciones presupuestarias en 1932 que obligaron a replantear la viabilidad de algunos de los proyectos que estaban en curso, entre otros, el del albergue de Antequera con la consiguiente apertura de un expediente de cesión del inmueble al Ministerio de Instrucción Pública y Bellas Artes para destinarlo a uso docente.

La oferta quedó sin efecto en 1934 y el Patronato reanudó la terminación del albergue, que se demoró hasta después de la guerra. La depuración profesional realizada a los arquitectos autores de los alberges determinó que se encargara la terminación de la obra al arquitecto del Catastro, Francisco Alonso Martos, y la inauguración del establecimiento se realizó el 14 de abril de 1940. El albergue fue ampliado en los años cincuenta por el arquitecto del Ministerio de Información y Turismo, Julián Luis

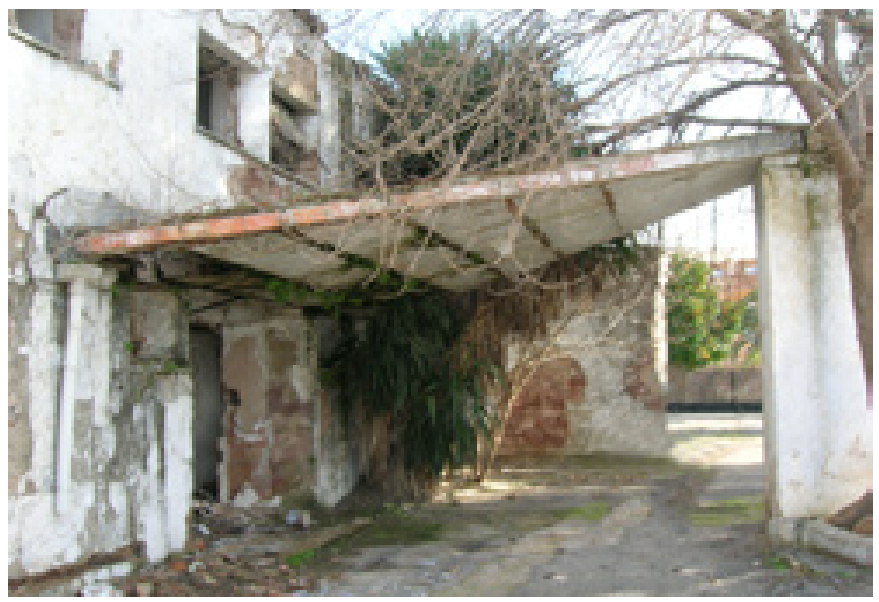

Ruina del albergue de carretera en Bailén (2014) f foto autores 


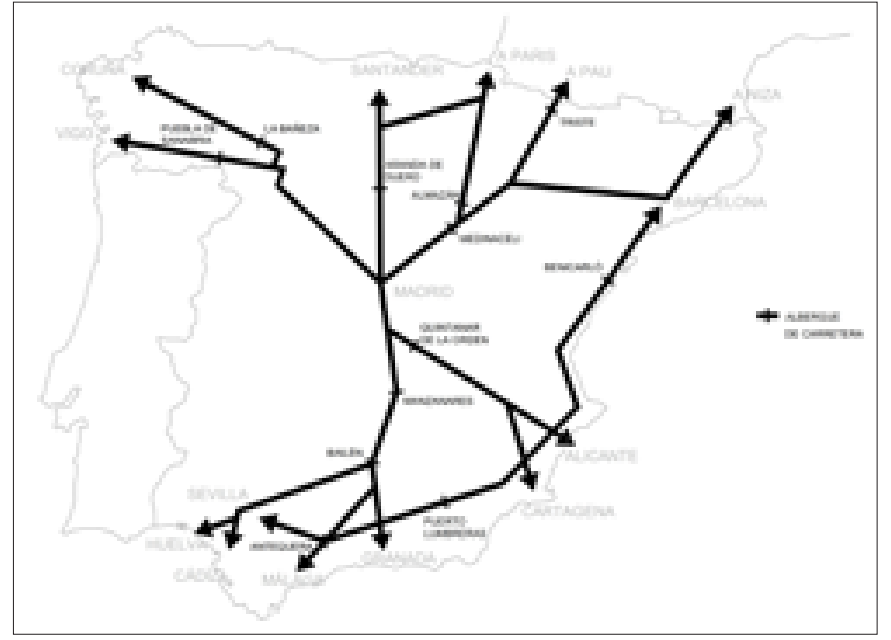

Albergues de carretera del Patronato Nacional del Turismo (1931-1939) | foto elaboración propia a partir del plano mural del albergue de Manzanares (Ciudad Real)

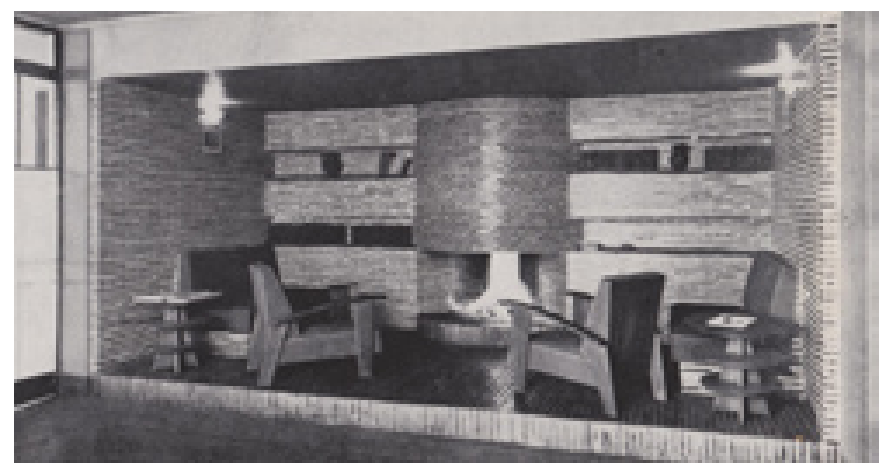

Zona de la chimenea del albergue de carretera en Manzanares (ca. 1930) | fuente Arquitectura, agosto 1931, n. ${ }^{\circ} 148$, p. 265

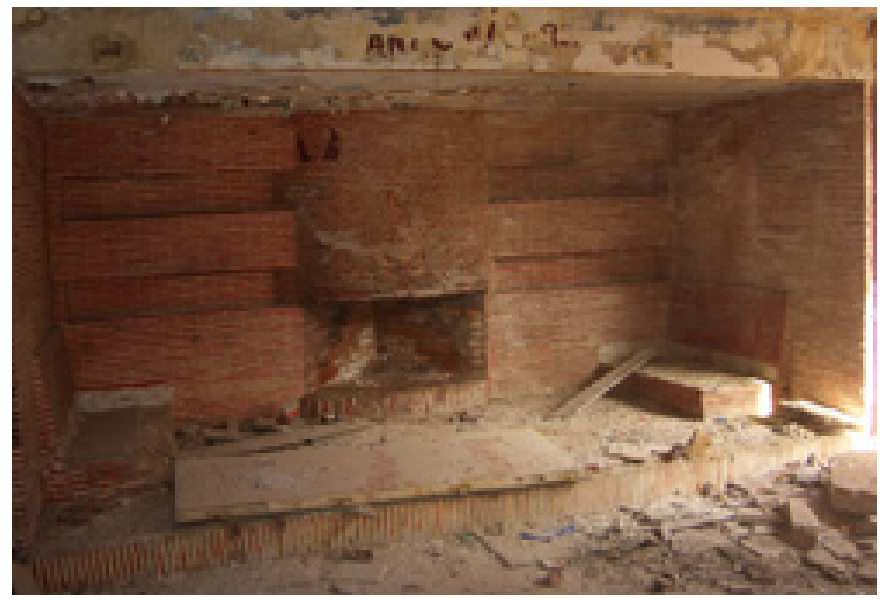

Zona de la chimenea del albergue de carretera en Bailén (2014) | foto autores
Manzano Monís, que incrementó notablemente su volumen construido, tanto en altura como en planta, dentro de los estrechos márgenes de espacio de su parcela. En los años sesenta las nuevas demandas hoteleras supusieron el abandono del albergue y una nueva cesión de terrenos municipales para construir de nueva planta y a cargo del mismo arquitecto. Al igual que en Bailén el antiguo albergue sirvió como edificación auxiliar del parador hasta mediados de los años noventa, cuando se revirtió al Ayuntamiento, que acabaría demoliendo el edificio a comienzos del nuevo siglo.

\section{Situación en el siglo XXI}

Los albergues de carretera de Bailén y Antequera forman actualmente parte del listado de patrimonio singular elaborado por el Instituto Andaluz del Patrimonio Histórico, pero sin catalogación efectiva. El de Antequera se demolió y el de Bailén se encuentra hoy cerca de ese trance debido a su avanzado estado de ruina. La falta de uso, de mantenimiento y el paso del tiempo convierten a los inmuebles en un problema para sus propietarios, que terminan prefiriendo su eliminación ante la posibilidad de producir daños a terceros debido a su estado de ruina.

El caso del albergue de Bailén es singular ya que hasta ahora ha permanecido en manos públicas como patrimonio del Estado, aunque cedido su uso a una entidad privada desde los años noventa, que explota el antiguo parador, hoy hotel, situado de forma adyacente. El albergue se encontraba en estado de abandono cuando se cedió su uso y hoy esa situación se ha convertido en ruina efectiva.

Otros albergues como los de La Bañeza (León) y Antequera desaparecieron bajo la acción de la piqueta por falta de utilidad y abandono progresivo, que los convirtieron en un problema para sus propietarios. El albergue de Bailén es todavía hoy un exponente vivo de la antigua red de albergues de carretera del Patronato Nacional del Turismo y un testimonio de la arquitectura anticipadora del Movimiento Moderno, que no debería dejarse desaparecer y que al menos debería ser catalogado para evitar la pérdida de su legado. 